Vietnam Journal of Mechanics, VAST, Vol. 26, 2004, No.4 (193 - 207)

\title{
SUSPENDED SEDIMENT TRANSPORT IN COASTAL ZONE BY TIDAL FLOW PART II: COMPARISON WITH THE EXPERIMENT
}

\author{
Antsyferov S. M. And Akivis T. M. \\ Russian Academy of Sciences, P. P. Shirshov Institute of Oceanology, \\ Nakhimovsky prospect, 36, Moscow, 117997, Russia
}

\begin{abstract}
The aim of the study is to develop methods for prediction of the vertical distribution of characteristics of sand and aleurite sediment suspended by tidal flow for the averaging time either divisible by tidal period (the first order model) or much less than it is (the second order one). The bottom is assumed to be erodible with possible formation of ripples.

Part II: The solution developed was verified by the extensive data set of measurements in Bahia Blanca Bay in Western Atlantic using sediment traps. The methods of trap data interpretation and the procedure for comparison measured data with model results have been developed. The comparison results seem to be quite satisfactory for both types of models.
\end{abstract}

\section{Experimental conditions and methodical basis of measurements}

The observations suitable for verification of the models developed were carried out in 198990 by P. P. Shirshov Institute of Oceanology RAS and the Marine Ministry of the USSR in Bahia Blanca Bay in Western Atlantic, where a semi-diurnal tide is the major energy factor. The measurements were performed at three sites that differed noticeably from each other by their hydrodynamic and lithologic conditions (Fig. 1). The overall performance of the measurements conditions can be seen in Table 1 and sediment grain size distribution is shown in Table 2.

The frames up to $3.5 \mathrm{~m}$ high were set at each site with attached spars equipped with plastic cylindrical sediment traps of size $100 \times 75(\phi) \mathrm{mm}$ having 6 inlets of diameter 3.0 or 4.0 or $7.5 \mathrm{~mm}$ (Fig. 2). The change of the spars was performed during low tide stage. The inlets were closed by turn of the trap head before the change.

An extensive data set has been collected with exposures from half of tidal period to 30 periods. In different measurements, the frames were equipped for a different height. Some short expositions were supplemented by measurements performed by the special frame fastened to the anchored ship $1-2 \mathrm{~m}$ beneath the sea surface. Collected samples received combined (granulometric and water) analysis with separation up to 17 fractions in the range of $0.8-0.002 \mathrm{~mm}$.

The hydrodynamic support of the measurements was provided by Boskalis International company. The automatic recording system MW635, included sea level and wave gauge, two component "Marsh-McBirney" current meter and compass, was set near each 
station at $2-3 \mathrm{~m}$ above bottom at a special pile. The sampling rate was $1 \mathrm{~Hz}$ during 2 minutes in every 10 minutes.

An interpretation on trap data is the most important methodical aspect for the problems posed. Our trap works as a micro sedimentation tank. It can be opened or closed by turn of its head, which is the only location of small inlets. There are a number of works devoted to methodical problems in traps use (Antsyferov et al., 1983; Antsyferov, Kos'yan, 1986; Antsyferov et al, 1990 and others) but they refer mainly to the condition where relatively heavy suspended particles once caught by the trap cannot be washed out of it. The recommendations on real SPM concentration determination are given in these works for the case the capture of inhomogeneous particles is not of selective nature. But the conditions of our experiment differ noticeably from those discussed above. First, the problem of selective capture cannot be ignored here because of the sizeable proportion of light particles in sediment flux. The foundation for the method of this feature inclusion is set in Antsyferov, 1998. Further this matter will be discussed in detail.

Second, this method gives much more information on sediment transport by currents than that by waves. It is of fundamental importance that, under current action, the total mass of transported suspended matter and its discharge can be easily found. The particles mass of $i$-th fraction $W_{i}(y)$ transported by the flow at level $y$ where a trap is set can be calculated as follows:

$$
W_{i}(y)=\frac{\gamma_{i}}{\chi D} V_{i}(y),
$$

where $V_{i}(y)$ is the mass of particles from $i$-fraction settled in the trap, $D$ is the area of the trap inlets projection on a plane normal to the flow direction, $\chi$ is the coefficient depending on the inlet diameter, $\gamma_{i}$ is the ratio between coming in and settled masses of particles of $i$-th fraction, i.e. the function describing the selectivity of particles capture for $i$-th fraction.

And the mass of inhomogeneous sediment containing $n$ fraction is equal to

$$
W(y)=\frac{1}{\chi D} \sum_{i=1}^{n} \gamma_{i} V_{i}(y) .
$$

A time-averaged flux for the exposition time $t$ can be easily found too:

$$
G_{i}(y)=\frac{\gamma_{i} V_{i}(y)}{\chi D t},
$$

for $i$-th fraction and

$$
G(y)=\frac{1}{\chi D t} \sum_{i=1}^{n} \gamma_{i} V_{i}(y),
$$

for inhomogeneous sediment.

The corresponding expressions for SPM concentration look as follows:

$$
\begin{aligned}
C_{i}(y) & =\frac{\chi}{D \operatorname{tu}(y)} \gamma_{i} V_{i}(y), \\
C(y) & =\frac{\chi}{\operatorname{Dtu}(y)} \sum_{i=1}^{n} \gamma_{i} V_{i}(y) .
\end{aligned}
$$


Previous methodical study shows that formulae (6.1)-(6.6) is applicable until trap is filled by no more than $\frac{3}{4}$ of its volume (Antsyferov, Kos'yan, 1990; Antsyferov, et al., 1990). The probability for a particle to be settled in a trap depends on relationship between its settling velocity and the fluid velocity inside the trap. The latter is difficult for measuring but it is believed to depend directly on the current velocity $u(y)$ in the vicinity of the trap. One more parameter that controls the regime inside the trap is $\frac{\phi}{\Phi}$ where $\phi$ and $\Phi$ are the diameters of the inlet and the cylinder, respectively.

A series of methodical experiments were carried out at the first site in order to find the desired relationships. Simultaneous measurements were performed at several levels by the traps and by the pumps during the periods from 3 to 6 hours from the anchored boat board. The traps were used with the inlets diameters of 3,4 and $7.5 \mathrm{~mm}$. The samples from both traps and pumps were analysed with separation of the same 17 fractions.

The mass of particles caught by the trap $\left(V_{T, i}\right)$ was compared to that for the pump $\left(V_{B, i}\right)$ The range of $i=k, \ldots, n$ fractions that were not washed out (i.e. $\gamma_{i}=1$ ) was found among the total range of $i=1, \ldots, n$ fractions. For this range the ratio of sediment masses in both bathometers was the same for different fractions:

$$
\frac{V_{T, i}}{V_{B, i}}=\frac{V_{T, i+1}}{V_{B, i+1}} \quad(i \geq k) .
$$

For $i<k$ the values of $\gamma_{i}$ were found as

$$
\gamma_{i}=\frac{V_{B, i} \sum_{i=k}^{n} V_{T, i}}{V_{T, i} \sum_{i=k}^{n} V_{B, i}} \quad(i<k) .
$$

The normalization through the whole range of non-washable out fractions (see the sums in the denominator) helps to enhance the accuracy of the sought value determination. The most reliable result was drawn for the traps with the inlets of $\phi=3 \mathrm{~mm}$. It is presented in Fig. 3 and can be approximated by the formula:

$$
\gamma_{i}(y)=\exp \left\{5.0\left(\frac{\phi}{\Phi}\right)^{0.5}\right\}\left[1-\tanh \left(0.5 \ln \frac{\omega_{i}}{u(y)}+3.35\right)\right] .
$$

For $\frac{\omega_{i}}{u(y)}>10^{-2}$ the value $\gamma_{i}(y)$ is close to unity. This condition corresponds mostly to sandy and coarse aleurite sediment. In the range $\frac{\omega_{i}}{u(y)}>5 \times 10^{-4}$ the function (6.9) can be considered suitable for every region. At the same time, the data permit to find the limit beyond which fine suspended particles flocculate forming aggregates settling as a single whole. The aggregates settling velocities vary in the range $(2 \div 5) \times 10^{-2} \mathrm{~cm} / \mathrm{s}$ whilst settling velocity of fine particles the aggregates consist of, that appear in (6.10), reaches $10^{-4} \mathrm{~cm} / \mathrm{s}$. Consequently $\gamma_{i} \cong$ const for a wide range of the ratio $\frac{\omega_{i}}{u}$. The values of settling velocities were found by the laboratory analysis where the aggregates have been broken into their components. It is known that, in natural conditions, such aggregates are quite stable and are not destroyed even under considerable velocities (Eims, 1982). In such a way settling velocity of aggregates can be found. 
It should be remembered that the size of aggregates and therefore the position of the asymptotic values for fine particles (Fig. 3, dashed lines) could vary depending on local conditions. So new regional coefficients should be found for the range $\frac{\omega_{i}}{u(y)}<5 \times 10^{-4}$. But if aggregates were not form the approximation by the data for unflocculated particles would be more suitable (see solid lines in Fig. 3):

$$
\gamma_{i}(y)=\operatorname{coth}\left[2.95\left(\frac{\phi}{\Phi}\right)^{-0.75}\left(\frac{\omega_{i}}{u(y)}\right)^{0.67}\right] .
$$

For the case of steady flow or in the context of the first order model, the correction factor $\widetilde{\gamma}$ for the whole sample can be easily found using known properties of entrapped particles:

$$
\widetilde{\gamma}=\frac{\sum_{i=1}^{n} V_{i} \gamma_{i}}{\sum_{i=1}^{n} V_{i}} .
$$

The same data allow finding the average settling velocity of suspended particles:

$$
\bar{\omega}=\frac{\sum_{i=1}^{n} V_{i} \gamma_{i} \omega_{i}}{\sum_{i=1}^{n} V_{i} \gamma_{i}} .
$$

The dependence on inlets diameter $\phi$ is set (see (6.9), (6.10)) using experiments with the traps of $\phi=3 \mathrm{~mm}$, so it is reasonable to be checked for traps with the other size of inlets. The opportunity to do this will occur some later.

Table 1. The overall performance of measurements conditions in Bahia Blanca Bay

\begin{tabular}{|c|c|c|c|c|c|}
\hline $\begin{array}{c}\text { Site } \\
\text { number }\end{array}$ & $\begin{array}{c}\text { Number } \\
\text { of } \\
\text { measurements }\end{array}$ & $\begin{array}{c}\text { Duration of } \\
\text { measurements, } \\
\text { hours }\end{array}$ & $\begin{array}{c}\text { Mean } \\
\text { depth }\end{array}$ & $\begin{array}{c}\text { Maximum } \\
\text { amplitude } \\
\text { of tidal wave } \\
\mathrm{m}\end{array}$ & $\begin{array}{c}\text { Maximum depth- } \\
\text { averaged flow } \\
\text { velocity } \\
\mathrm{m} / \mathrm{s}\end{array}$ \\
\hline 1 & 47 & $3.0-258$ & 5.5 & 2.5 & 1.2 \\
\hline 2 & 27 & $4.5-470$ & 9.0 & 1.8 & 1.0 \\
\hline 3 & 18 & $93.3-695$ & 12.0 & 1.0 & 0.7 \\
\hline
\end{tabular}

Table 2. Granulometric composition of bottom material, $\%$

\begin{tabular}{|c|c|c|c|c|c|c|c|c|c|c|c|}
\hline $\begin{array}{c}\text { Fraction } \\
\text { number }\end{array}$ & 1 & 2 & 3 & 4 & 5 & 6 & 7 & 8 & 9 & 10 & 11 \\
\hline $\begin{array}{c}\text { Grain } \\
\text { size } \\
\text { mm }\end{array}$ & $<0.005$ & $0.050-$ & $0.063-$ & $0.08-$ & $0.100-$ & $0.125-$ & $0.16-$ & $0.20-$ & $0.250-$ & $0.315-$ & 0.50 \\
\hline Site 1 & 1.5 & 0.063 & 0.080 & 0.10 & 0.125 & 0.160 & 0.20 & 0.25 & 0.315 & 0.500 & 0.80 \\
\hline Site 2 & 0.5 & 0.2 & 0.5 & 1.2 & 4.7 & 3.5 & 4.4 & 6.0 & 12.0 & 55.0 & 12.0 \\
\hline Site 3 & 4.7 & 6.8 & 14.2 & 23.6 & 32.1 & 1.7 & 4.4 & 1.0 & 1.0 & 0.5 & - \\
\hline
\end{tabular}




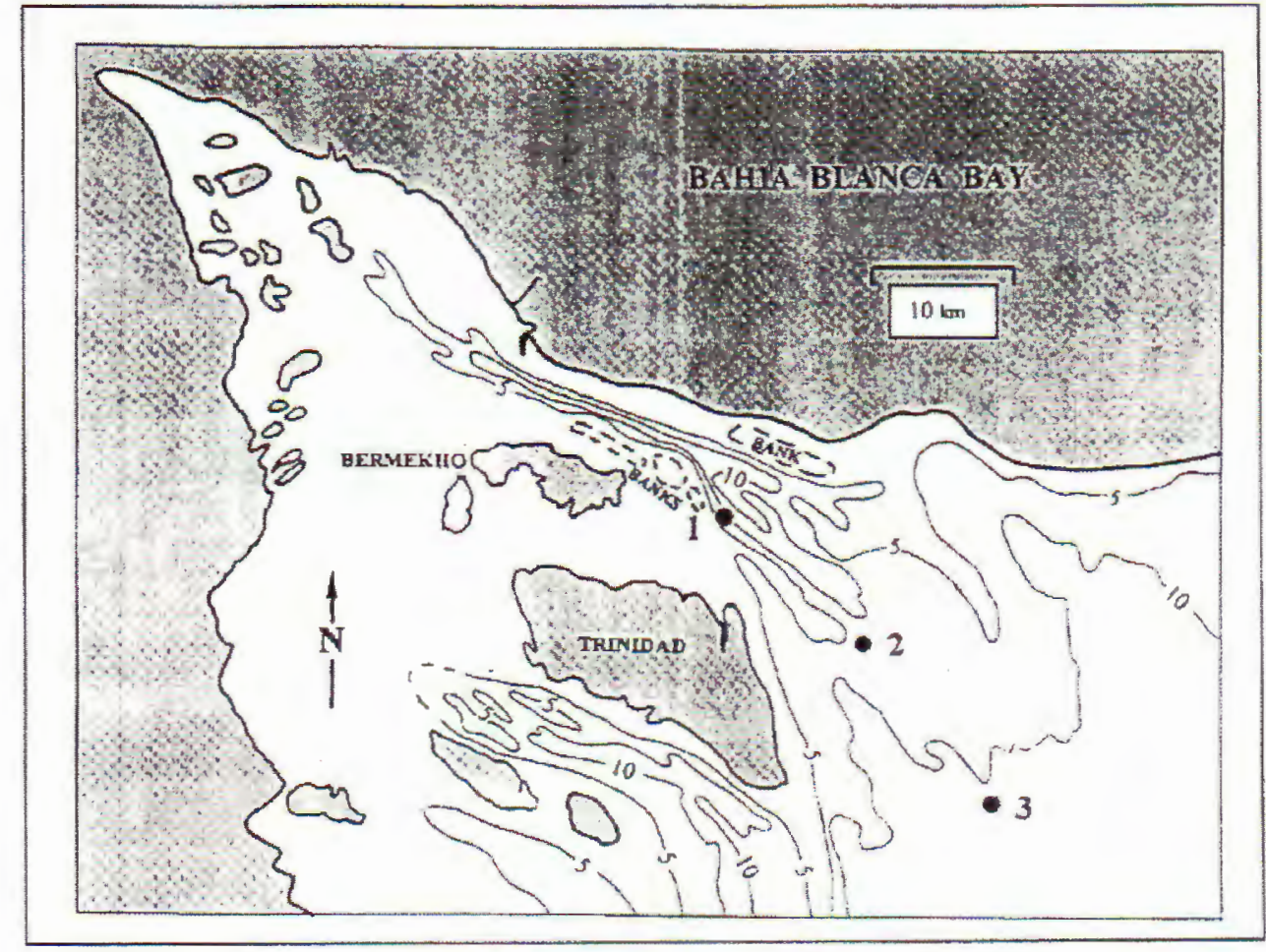

Fig. 1. Observational sites locations in the Bahia Blanca Bay

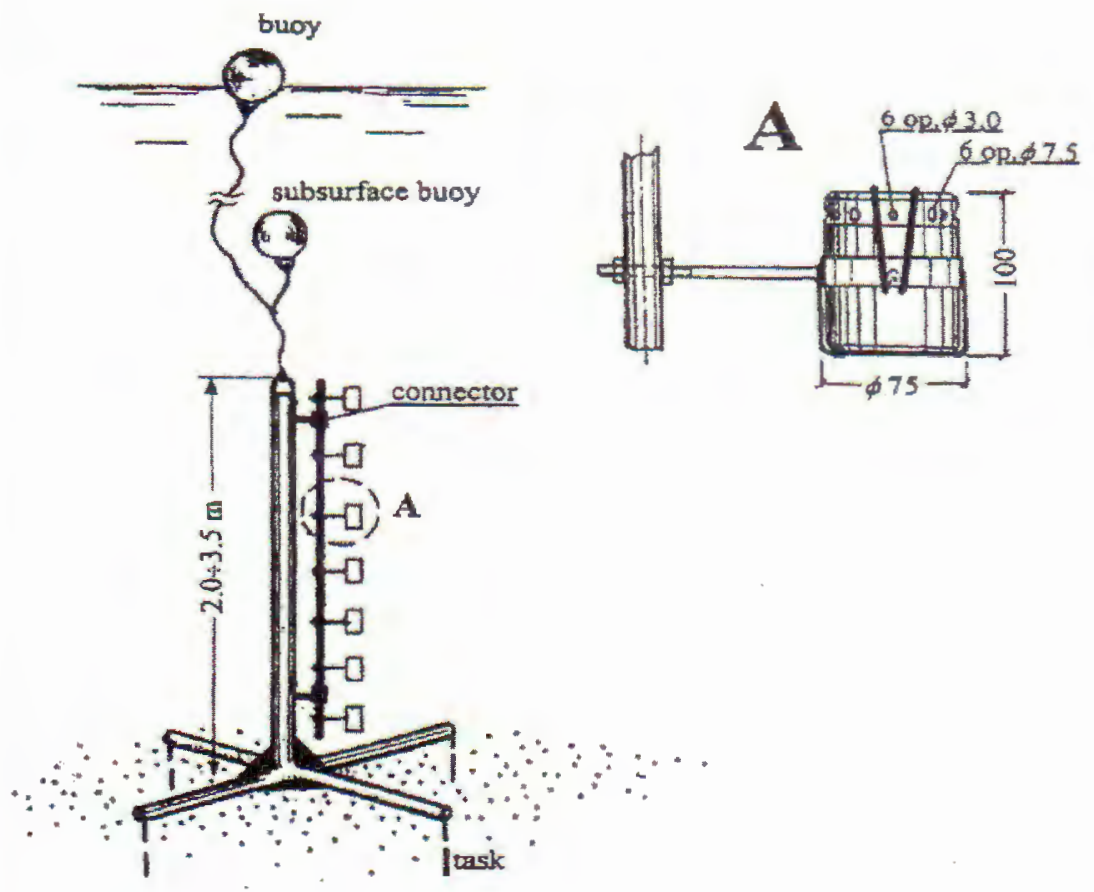

Fig. 2. A sketch of the frame station equipped with sediment traps 


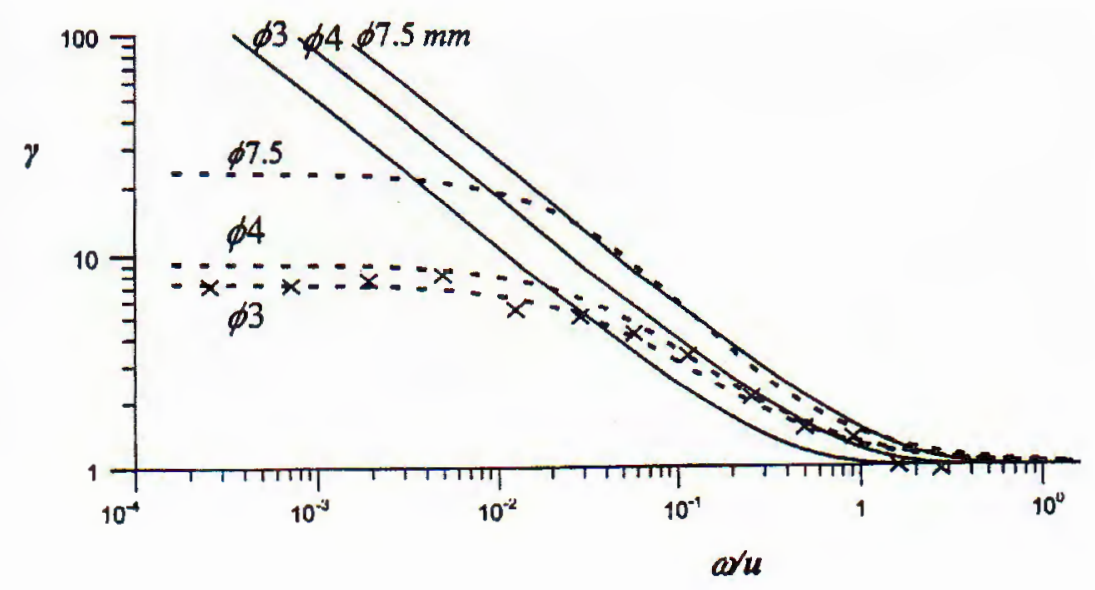

Fig. 3. The selectivity coefficient for the traps against the ratio betweenthe particles settling velocity and flow velocity for different inlets diameters. Crosses show measuring data, dashed and solid lines represent the results of calculation by the formulae (6.9) and (6.10), respectively

\section{Comparison with the experiment}

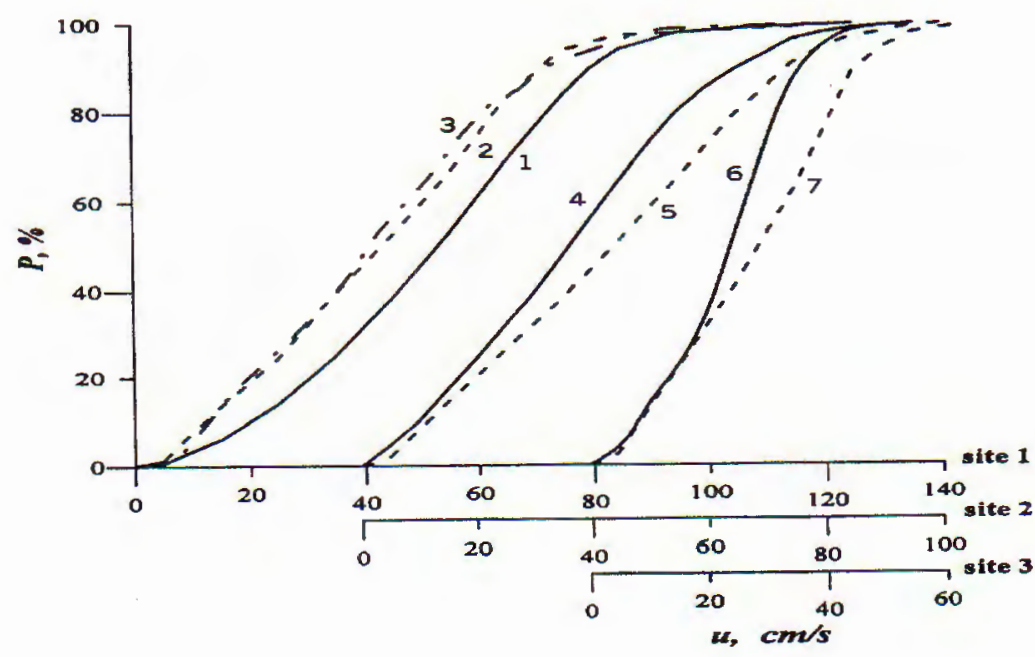

Fig. 4. Current velocity distribution for the expositions used for the model verification.

The first site: 1 -duration is 8 tidal periods, the gauge level is $c=3.2 \mathrm{~m}$ above the bottom;

$2-2$ periods, $c=2.3 \mathrm{~m} ; 3-\mathrm{a}$ half of the tidal period (the flood), $c=2.2 \mathrm{~m}$

The second site: $4-28$ periods, $c=3.8 \mathrm{~m} ; 5-1$ period, $c=3.4 \mathrm{~m}$

The third site: $6-25$ periods, $c=2.3 \mathrm{~m} ; 7-5.5$ periods, $c=4.2 \mathrm{~m}$ 
The measuring data collected at three sites for the periods of weak wave activity were chosen to verify the solutions. The detailed measurements of different exposition time in a sufficiently thick near-bottom layer were chosen. One of the experiments included measurements in near-surface layer as well when the traps have been set at the frame fixed under the sideboard of anchored vessel. The velocity profiles plotted by measurements at some certain horizons are shown in Fig. 4.
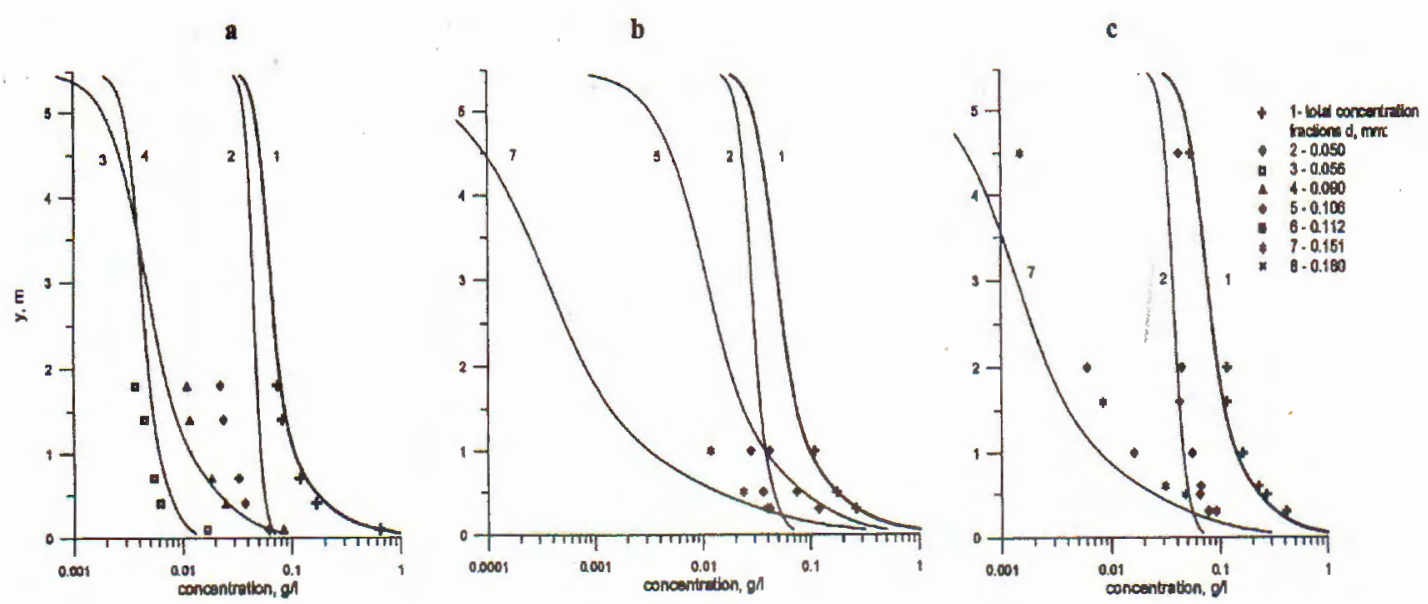

Fig. 5. Comparison between the first order model results and the observational data for the first site

a - Averaging time is 8 tidal periods (exposition 1, Fig. 4);

b -2 periods (exposition 2)

c- flood phase (exposition 3).

The fractions are represented that do not overload the figures.

According to almost all known relief type classifications (see, for example, Van Rijn, 1993; Znamenskaja, 1992) the local hydrodynamics and average grain size must result in rippled bed. There was no opportunity to carry out direct observations of bottom relief because of complete opacity of the water. But it was ascertained that, in low water state, the bottom were covered by silt or algae at the third site and remained clear at the first and the second ones. Fine particles constitute an appreciable part of sediment at the third site (see Table 2). By these reasons the effect of cohesiveness and relief deformations underdevelopment can appear at the third site (Torfs et al, 1992; Van Rijn, 1993). Thus, only the measurements carried out at the first two sites can be considered as reliable data for verifying the models of suspended sediment distribution over the rippled bed. The data collected at the third site are unrepresentative for our purpose. The model for rippled bed is more complicated than that for flat one but this condition is more often met in coastal zone of tidal seas.

The verifying method for the first order models does not represent considerable difficulties. The effective hydro-dynamical parameters chosen above were used for the comparison 
of concentration profiles for both total mass of suspended sediment and individual fractions. The experimental values of concentration were found by formulae (6.5), (6.6) using values $V_{i}(y)$ and $V(y)$ obtained as a result of each exposure. The comparison results can be seen at Figs. 5, 6. For the first two sites they can be considered as wholly satisfactory for the total suspended sediment mass as well as for the leading sediment fractions. As would be expected, the correspondence for the total concentration was better compared to that for separate fractions. This result allows believing the larger discrepancies between measured and calculated concentrations for some fractions to be caused by statistical errors inevitable under such a detailed separation. It is important that the results are good not only for fine fractions which relative concentration profile is described properly by Rouse formula but for coarser particles as well when the contribution of the inertial correction is no less significant.
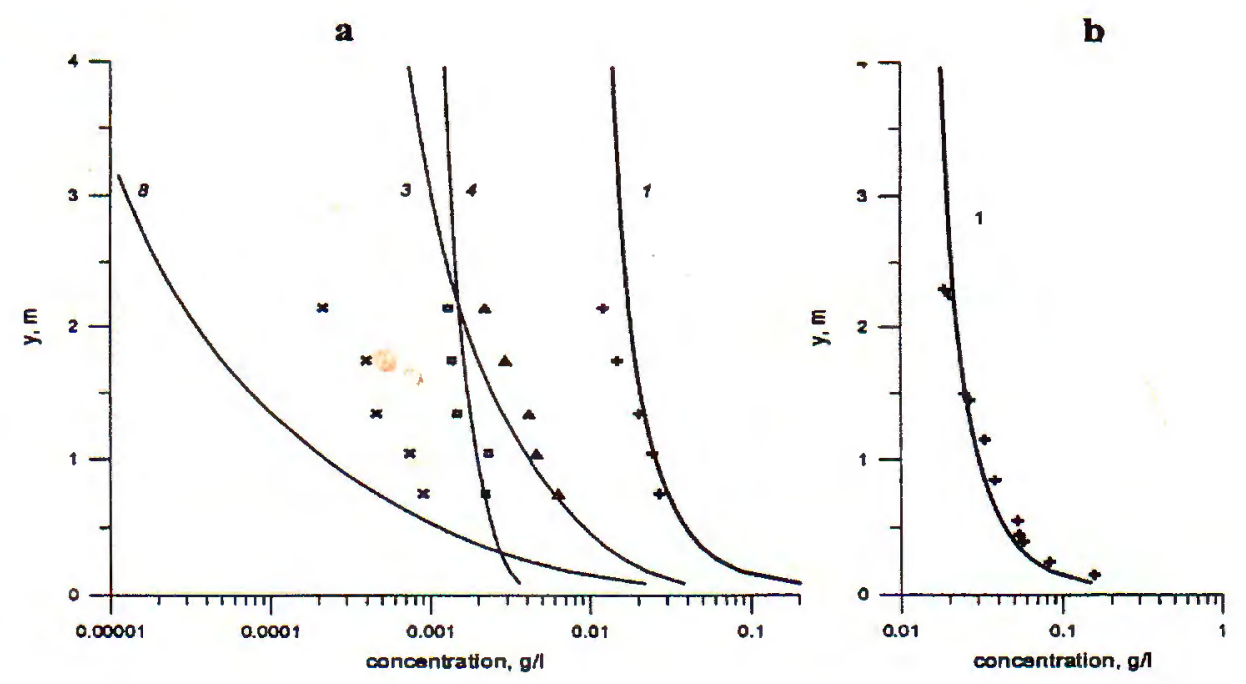

Fig. 6. Comparison between the first order model results and the observation data for the second site a - Averaging time is 28 tidal periods (exposition 4, Fig. 4)

b -1 period (exposition 5)

See Fig. 5 for the symbols.

The comparison for the third site was made for assessing how much sediment pick up and bed relief development are affected by the condition mentioned above, i.e. silting up of the bed and effects of cohesiveness. To this end, consideration of the total concentration is sufficient rather than analysis of separate fractions. One of the results is represented at Fig. 7 where the measured values are noticeably less than those calculated by the model for developed rippled bed. This issue will be discussed below whereas the second order models will be verified.

Thus, the choice of effective characteristics of the flow is admissible and, for the stipulated conditions, the prediction problem on time-averaged SPM is solved reliable enough for time intervals divisible by tidal period. Noticeable discrepancies were found for heavy fractions only. But their part in the total suspended sediment mass is negligible. 


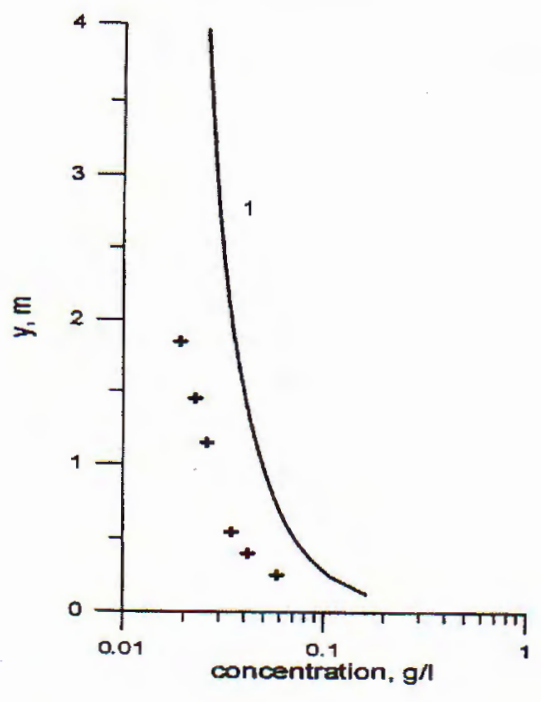

Fig. $\%$ Comparison between the first order model results and the observation data for the third site: averaging time is 25 tidal periods (exposition 4, Fig. 4) See Fig. 5 for the symbols.

This result gives possibility for verifying the solution of selectivity problem for particles capture by the traps with inlets of different diameters. There are several ways to do it. One of them is comparison of the results of suspended particles average settling velocity calculation using the data of sediment masses settled in the traps with different inlets diameters. Several experiments were carried out at the first two sites, with the traps with different inlets fixed at the same frame. Then average settling velocity of suspended sediment was calculated by formulae (6.9), (6.12) using the measured data. The dashed lines at Fig. 8 represent fitting of the experimental data on average settling velocity of entrapped sediment (symbols) while the solid lines show the fitting curves for calculated average settling velocity of suspended sediment. As far as the calculations for the traps with different inlets diameters are fitted well enough by the same curve the solution proposed seem to be quite reliable. Similar verification could be done by comparison calculated masses, fluxes or concentration of sediment particles caught by the traps with different inlet diameters (formulae (6.1)-(6.4) and (6.9)).

The verifying of the second order models is the more complicated procedure. Here, the values to be compared are the measured data on entrapped masses of particles and the corresponding values computed by the model. The measurements described above give the values of the total mass of sediment caught by the traps, $V^{(\text {meas) }}(y)$, and the component masses of each $i$-th $(i=1, \ldots, n)$ fraction (so, $V^{\text {(meas) }}(y)=\sum_{i=1}^{n} V_{i}^{\text {(meas) }}(y)$ ). Apparently, these values are obtained during the total exposition period, which is divided for modelling purpose into $m$ time steps. The entrapped mass of $i$-th fraction particles during $j$-th time step computed by the model using the results of methodical study $(6.5),(6.6),(6.9)$ is given by the formula

$$
V_{i, j}^{(\text {calc })}(y)=\frac{D \chi}{\gamma_{i, j}(y)} C_{a, i, j} R_{i, j}(y) F_{i, j}^{Q(z)} u_{j}(t) t_{j} .
$$


Summing over time steps gives the mass of $i$-th fraction $V_{i}^{(\text {calc })}(y)=\sum_{j=1}^{m} V_{i, j}^{(\text {calc })}(y)$ and follow-up summing over fractions gives the total mass of sediment $V^{(\text {calc })}(y)=\sum_{j=1}^{m} V_{i}^{(\text {calc })}(y)$ entrapped during the total exposition period. These values are to be compared with corresponding measured ones, i.e. $V_{i}^{(\text {meas })}(y)$ and $V^{\text {(meas) }}(y)$

It should be mentioned that the granulometric data for sediment settled in a trap is not necessary for comparison of measured and calculated masses of sediment, the information on bottom sediment composition is sufficient. Because of this the more extensive field data arrays can be engaged in the analysis than for the first order model.
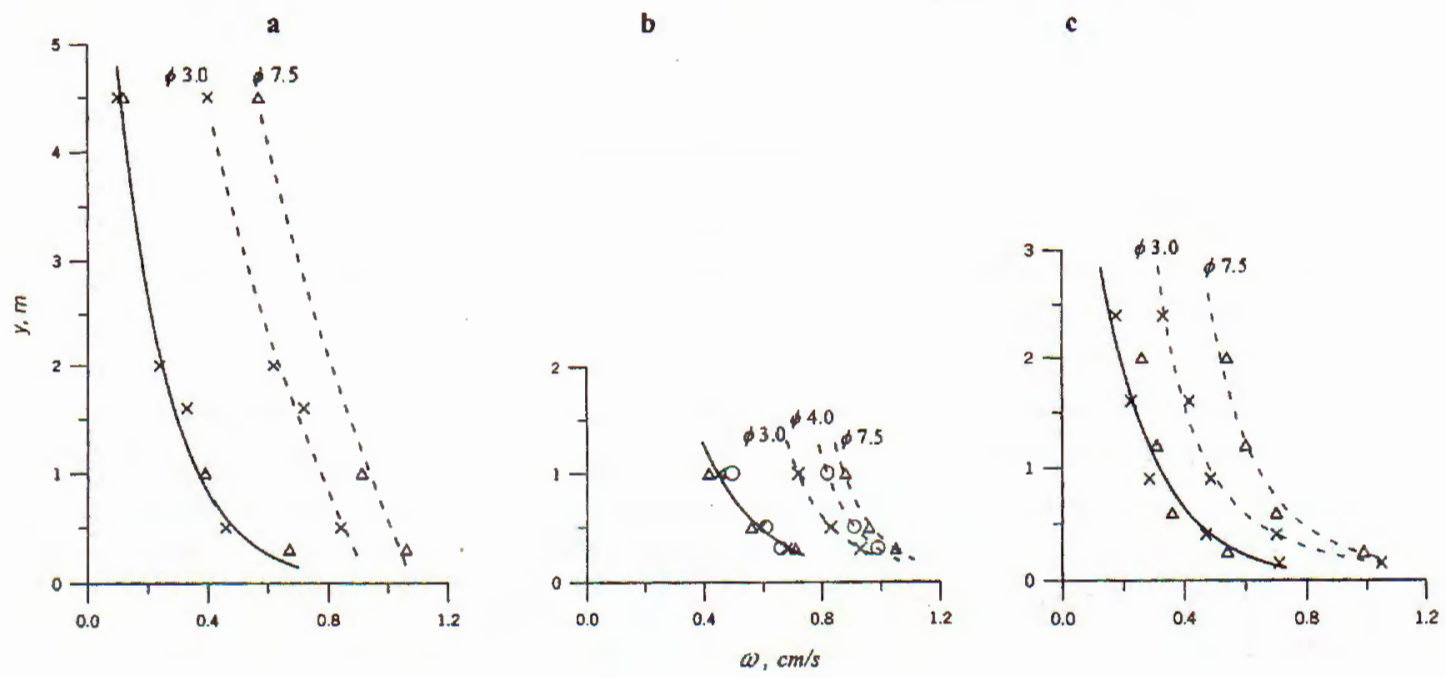

Fig. 8. Measured data on average settling velocity of entrapped sediment (symbols) fitted by dashed lines and the same calculated by (6.9), (6.10)

for suspended sediment fitted by solid lines:

$a$ - The first site, a half of tidal period (the flood)

b - The first site, 2 periods

c- The second site, 28 periods

The comparison results for the first two sites are shown on Figs. 9 and 10. They can be considered as quite satisfactory, at least for the total mass and for the most representative fractions. So, the second order model gives reliable solution for the prediction problem posed.

For the third site the total sediment mass is considered similar to the first two ones. The second order model enables us to compare measuring data with the modelling results for both flat and rippled bed. The most of measured values are between those calculated for flat and rippled bed (Fig. 11a). But in some rare cases the comparison results look quite sufficiently (see Fig.11b). During the latter exposition little waves (of average height 1 $\mathrm{m}$ and period $5 \mathrm{~s}$ ) induced near-bottom velocities slightly exceeding the pick-up threshold which prevented silt cover formation on the bottom. Hence no obstacles affected the 
development of the bottom relief. But this sort of condition was rarely observed due to short periods of waves action.
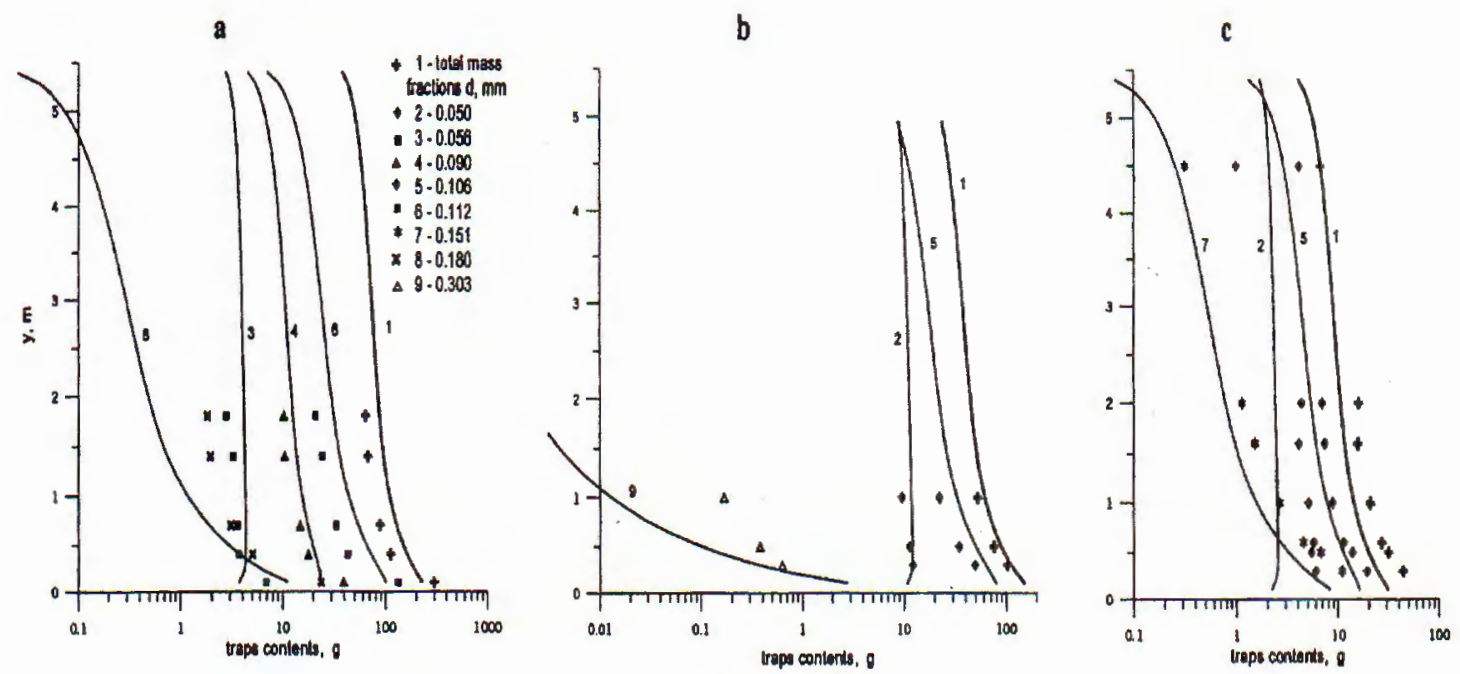

Fig. 9. Comparison between the second order model results and the data on the mass of entrapped sediment for the first site a - Averaging time is 28 tidal periods (exposition 4, Fig. 4)

$\mathrm{b}-1$ period (exposition 5)

c-Flood phase (exposition 3)

\section{Discussion}

It seems reasonable to identify the range of problems, which the models of the both first and second orders can be applicable to. The problems of long-period relief variability, sediment accumulation and erosion near hydraulic structures and many of ecological problems allow using the solutions with averaging time comparable to tidal period. But the second order model gives much greater potentiality for geophysical prognosis. It not only enables one to determine time variability of concentration and statistical characteristics of suspended sediment, but it can be used as a basis for the calculation of sediment transport in different directions. The latter needs measuring data on time variation of both current velocity value and direction or some tidal flow model providing the same parameters.

At the same time, the models under discussion have some pitfalls but their impact can be later on reduced or removed at all.

The models include a number of empirical elements but otherwise they could not be developed at present. Because of this, evidently, their applicability is restricted to the data span put into the base of the reliable solutions. By these criteria the allowable depth range is $5-1 \mathrm{~m}$. Taking into account the verifying method, the lower limit for the dynamical characteristics should be assumed as $\frac{\bar{\omega}}{v_{* e f}}<0.6$. The upper limit can be specified by the 
bottom forms erasing condition (Znamenskaya, 1992). The models are to be expected to work reliable enough for the lesser depths because they developed on the base of results obtained in "laboratory range" of depths. Hopefully, the models will work well in the same depth range for the intensive stage of tidal period when $\frac{\bar{\omega}}{v_{* e f}}>0.6$ corresponding to bed form erosion (i.e. flat bed) because most of the basic experiments were carried out under flat bed condition. Unfortunately, this guess cannot be proved at present for the lack of appropriate field experimental data. The methods developed are expected to describe adequately sediment transport in estuaries and river mouths reaches where fluvial flow is superimposed on the tidal one.

One more negative consequence of empirical units is that the second order model gives reduced near-bottom values $V_{i}(z)$ for light fractions contradicting to measured ones. But this is minor discrepancy (Figs. 9, 10).

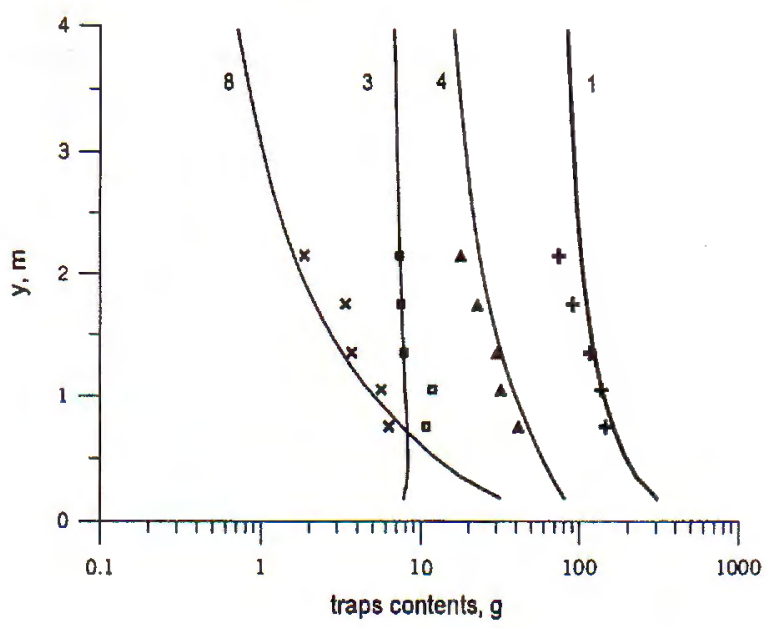

b

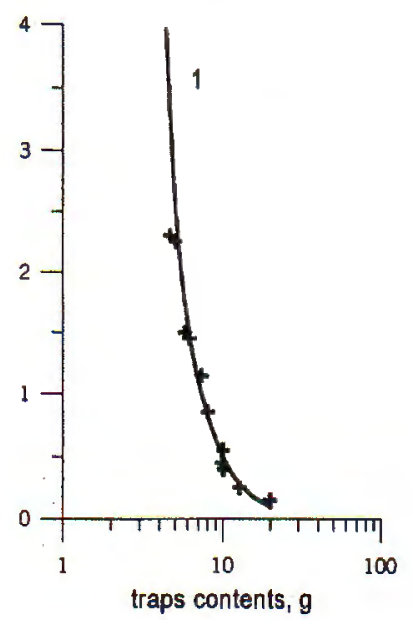

Fig. 10. Comparison between the first order model results and the data on the mass of entranpped sediment for the second site a - Averaging time is 28 tidal periods (exposition 4, Fig. 4) b -1 period (exposition 5)

See Figs. 5 and 9 for the symbols.

Some factors are not considered properly in the solutions. So, it is wrong to believe that the total reconstruction of bottom relief occurs at each step of the tidal period. It is known that under weak current regimes the bed forms can exist inherited from intensive regimes of current-bed interaction. Hence, the bottom relief under low current velocities is not unlikely to correspond to more intensive regime.

Besides, the comparison results show that some more heavy particles can be picked up than the models predict. The distribution of comparatively heavy particles is more uniform than that predicted and the higher the current velocity the more this discrepancy. This is clearly seen from the comparison of the concentration profiles for the fraction 0.18 
$\mathrm{mm}$ at the first and the second sites (Figs. 6a, 9a, 10a). Again, this is the consequence of the flat bed condition under which the pick-up criterion obtained. But the effect of local eddies coming from ripple crests probably leads to increase not only the mass but also the size of suspended particles.

It should be emphasized again that the natural situation used for verification is much more complicated and many-sided than that described by the model. One more factor, which is not taken into consideration in the model, is sediment feeding from the neighbouring areas. The verification of the model assumes the measurement site and its neighbourhood have the same granulometric distribution of bottom sediment. The dimensions of the neighbourhood is determined by the transport scale, i.e. the tide duration and the current velocity. For the first site, the "zone of infection" has rather complicated relief including even some banks, which result in potential variability of bottom sediment composition. Near the second site, the relief has quite a plane structure and the bed sediment has, to all appearance, the uniform composition. Correspondingly, the discrepancy between measured and calculated values at the first site is greater than at the second one (see Figs.5, 6, 9 and 10). The third site has quite a plane relief too but the bed here is covered with algae and because of this the less amount of sediment came into suspension than the model predicts (see Figs. 7,11 ).
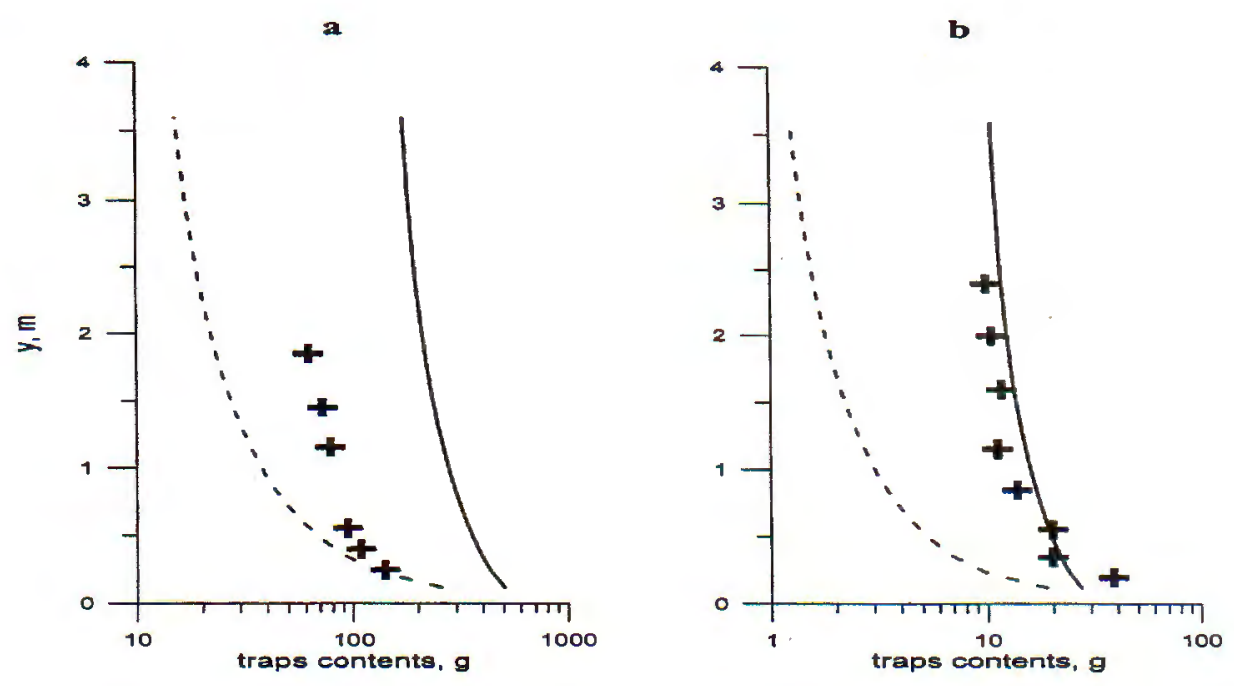

Fig. 11. Comparison between the first order model results and the data on the mass of entrapped sediment for the third site a - Averaging time is 25 tidal periods (exposition 6, Fig. 4) $\mathrm{b}-5.5$ period (exposition 7 ). Solid lines show the results for the rippled bed, dashed ones - for the flat bed See Fig. 5 and 9 for the symbols.

But the developing of the methods for more adequate consideration is the matter of future research. 
Acknowledgements. The authors acknowledge the support of the Russian Foundation for Basic Research (RFBR) through grant No 00-05-64383 and INTAS through grant No 99-1600.

\section{References}

1. Antsyferov S. M., Measurements of suspended sediment transport in river mouths and estuaries, Hydrotech. Constr. Plenum Publ. Corp. 32 (4) (1998) 193-197.

2. Antsyferov S. M., Basinski T., Pykhov N. Y., Measurement of suspended sediment concentration, Coastal Eng. 7 (1983) 145-166.

3. Antsyferov S. M., Debol'skii V. K., Distribution of suspended matter concentration in steady-state flow over an eroding bed. Water Resources 24 (3) (1997) 244-250.

4. Antsyferov S. M., Kos'yan R. D., Suspended Sediment on the Upper Shelf, Moscow. "Nauka" Publ. House, 1986.

5. Antsyferov S. M., Kos'yan R. D., Study of suspended sediment in the coastal zone, Coastal Eng. 14 (1990) 147-172.

6. Antsyferov S. M., Pykhov N. V., Dachev V. Zh., Dynamics of Suspended Sediments, Dynamical Processes in Coastal Regions, Results of the Kamchia Int. Project. Sofia.: Publ. House of the Bulg. Acad. of Sci., 1990.

7. Clarke T. L., Lesht B. M., Yong R. A., et al., Sediment resuspension by surfase-wave action: an examination of possible mechanisms, Mar. Geol. 49 (1982) 43-59.

8. Debol'skii V. K., Antsyferov S. M., Akivis T. M., The Prediction Problems of Suspended Sediment Distribution in Channel and tidal Flow, Water Problems at the Edge of the Century, Moscow. "Nauka" Publ. House, 1999.

9. Eims D., Flocculation of suspended sediment matter in coastal waters, Particle Flux in the Ocean, Mitt. Geol.-Paleont. Inst. Univ. Hamburg. Heft 62, 1982.

10. Grant W. D., Madsen O. S., Moveable bed roughness in unsteady oscillatory flow, J. Geophys. Res. 87 (1982) 469-481.

11. Kantardgi I. G., Antsyferov S. M., Development of coastal sediment modelling, Wave and current co-action, $5^{\text {th }}$ Int. Conf. on Coastal and Port Eng. in Developing Countries, Proc. COPEDEC. Cape Town., 1, 103-114.

12. Kos'yan R. D., Pykhov N. V., Edge B. L., Coastal Processes in Tideless Seas, ASCE Press, 2000.

13. Marchuk G. I., Kagan B. A., Dynamics of Ocean Tides, SPB, Gidrometeoizdat Publ. House, 1991.

14. Neill J., Note on initial movement of coarse uniform bed material, J. Hydr. Div., Proc. of ASCE, 2, 1968.

15. Rossinskii K. I., Debol'skii V. K., Fluvial Sediments, Moscow. "Nauka" Publ. House, 1980.

16. Torfs H., Williamson H., Huysentruyt H., Setting and erosion characteristics of mud/sand mixtures, Proc. Coastal Dynamics'95, ASCE N. Y., 749-758, 1995.

17. Van Rijn L. C., Principles of Sediment Transport in Rivers, Estuaries and Coastal Seas, Aqua Publ., Amsterdam, 1993.

18. Yu G., Fang D., Threshold velocity of sand mixtures, Proc. $26^{\text {th }}$ Congr. of IAHR, Thomas Telford, London, 1995. 
19. Zheleznyakov G. V., Debol'skii V. K., On Rippled Movement of Sediments of Different Density, Dokl. VASKHNIL, 2, 1971.

20. Znamenskaya N. S., Hydraulic Modelling of Channel Processes, SPb, Gidrometeoizdat Publ. House, 1992.

21. Zyryanov V. N., Reshetkov A. B., Sediment transport and sea floor transformation by tidal waves in shallow water, Oceanology 38 (5) (1998) 674-686.

Received November 14, 2003

\section{SỰ VẬN CHUYỂN BÙN CÁT LƠ LỬNG Ở VÙNG BỜ BỞI DÒNG TRIÊU PHẦN II: SO SÁNH VỚI THÍ NGHIỆM}

Mục tiêu của nghiên cứu này là phát triển phương pháp dự báo các đặc trưng phân bố theo phương thẳng đứng của bùn cát lơ lựng do dòng triều với thời gian trung bình hoá là chu kỳ triều (mô hình bậc nhất) hoặc nhỏ hơn nhiều lần (mô hình bậc hai). Đáy biển được coi là có khả năng bị xói và có khả năng tạo thành gợn sóng lăn tăn.

Phần II: Lời giải của các mô hình được phát triển đã được kiểm tra băng các chuỗi số liệu đo đạc bằng bẫy bùn cát ở vịnh Bahia Blanca phía tây Đại Tây Dương. Những phương pháp nội suy các số liệu này cũng như cách thức so sánh số liệu do đạc với kết quả của mô hình đã được phát triển. Các kết quà so sánh dường như hoàn toàn thoá mãn đối với cà 2 mô hình. 